\title{
Italians and Foreign Immigration
}

\author{
CORRADO BONIFAZI, Director of Research \\ Institute for Research on Population and Social Policy, Rome \\ National Research Council (CNR), Italy
}

\begin{abstract}
Opinion surveys on attitudes towards immigration are becoming more and more important, owing to the increasing role of political debate on migration issues in Western European countries. CNR has conducted four surveys on this topic, collecting data on the evolution of Italians' attitudes towards migration issues. In fact, the first survey was conducted in the second half of the eighties, when foreign immigration was in its early stages. The last survey took place in 2002, when immigration was already well established in Italy. The article focuses on three main issues: the global impact of immigration on Italian society, the immigrants' role in the labour market, and immigration policy. In general, the results of the last survey confirm a trend that appeared already in 1997, of more balanced and realistic opinion that were less of a response to circumstances perceived as "special emergencies". Highly educated people, teachers and students continue to be the most open and receptive groups, whereas the less favourably inclined and more worried continue to be old people, those with less education, the unemployed, housewives, and retirees.
\end{abstract}

Keywords: International migration, Italy, opinions towards immigration.

\section{Introduction}

The problems connected to the immigration phenomenon are reflected with increasing intensity in the public opinion of developed countries. The trend concerns practically all countries with extensive immigration. It has developed in response to growing migration flows, the increased political importance of regulatory measures for addressing the incoming flows, and the entry and integration of migrants. This situation has stimulated an interest in observing and monitoring, through field surveys, opinions towards immigration, immigrants and immigration policies. In the United States, the first attempts to gather information on these issues through opinion surveys date back to the 1930's, whereas in Europe surveys were widely utilised in France in the 1950's (Bonifazi 1996). We are witnessing a visible renewal of interest in these surveys, 
also from a cross-country perspective (Espenshade and Hempstead 1996; Simon and Lynch 1999; Söderling 1999; Maddens et al. 2000; Bauer et al. 2000; Dustmann and Preston 2001; Moors et al. 2001; Gang et al. 2002; Mayda 2004; Ervasti 2004). By and large, two different points of view have been analysed to explain attitudes towards immigration, attributing prejudice either to socio-economic causes or to cultural factors (Ervasti 2004). Many theoretical hypotheses have been tested and the role of various factors analysed. Among other factors, researchers have considered labour market competition, cultural affinity, cost-benefit considerations, welfare concerns, and the role of immigration policies as possible determinants of the native-born population's attitudes towards immigrants.

In Italy, the analysis of public opinion positions towards immigration has spawned several surveys. Among those carried out on a national level we point to surveys by the Institute for Population Research (IRP) and the Institute for Research on Population and Social Policy (IRPPS) of the National Research Council (CNR); those prompted by the Commission for the Policy of Integration of Immigrants and carried out by the Institute of Public Opinion Studies (1999 and 2000); the surveys by Doxa (1999); and those by the North-East Foundation, carried out simultaneously in Italy and other European countries (Diamanti 2001; Diamanti and Bordignon 2005)

Among these, the CNR surveys allow a temporal comparison of rather broad proportions, given that the first survey was carried out by IRP in 1987/1988 and the last one by IRPPS in 2002. Overall, this represents a fifteen-year period that saw some rather extraordinary changes in the dimensions and characteristics of foreign immigration in Italy. Foreign immigration appeared in Italy in the second half of the seventies and developed during the eighties, as in other former emigration countries in southern and northern Europe (Spain, Portugal, Greece, Finland and Ireland). The lack of appropriate immigration policies and the suspension of labour recruitment by traditional immigration countries have often been viewed as the two main causes for the new European destinations for migration flows. In southern Europe, the main economic sectors to use foreign labour usually include domestic services, low-skill services, agriculture, and building and construction. Also, to a large extent, the black labour market has contributed to the development of immigration that is consistent with the so-called Mediterranean model. In the nineties, political turmoil in Eastern Europe added to the considerable demographic and economic imbalances between countries and resulted in increasing migration flows. For example, in Italy at the time of the first survey (1987-88), there were 572,000 foreigners with permit to stay, but 15 years later their number had tripled to 1.5 million - a shift from 1 to $2.6 \%$ of the total population. The last regularization, in 2002, determined a further increase in the number of permits to stay holders to 2.3 million by the beginning of 2005 ( $4 \%$ of the population). Since the beginning of the nineties, the situation in Italy has also been characterised by the 
growing entry of immigrants into the industrial sector in many regions of the country. This is a consequence of a shortage of native workers resulting from low unemployment and demographic imbalances between labour supply and demand, at the same time as an ageing population has increased the need for foreign labour in elder-care services. As regards the area of origin of immigrants, it has always been extraordinarily far-reaching, including the Far East, Latin America and Sub-Saharan Africa, as well as the Mediterranean Basin and Eastern Europe in Italy's immediate proximity. The latter area has been the source of a huge increase after the 2002 amnesty, because the proportion of Romanians, Ukrainians, Albanians, Poles and Moldavians was more than $50 \%$ of the 650,000 immigrants who were legalised.

CNR has carried out four surveys: apart from those just mentioned the other two were carried out by IRP in 1991 and 1997 respectively. In the first three a section on foreign immigration was included in the questionnaire of the surveys on the opinions and attitudes of Italians towards demographic trends (Bonifazi 1991, 1992, 1995, 1996; Bonifazi and Cerbara 1999; Bonifazi and Caruso 2000). The last survey examined the immigration through an an autonomous survey, which also allowed for an expansion of the questionnaire. Moreover, in 2002 the authors switched from direct interviews to telephone interviews, increased sample sizes, and updated characteristics in accordance with the new survey type ${ }^{1}$.

Thus, the data allows us to follow the evolution of Italians' opinions towards immigration almost from the very beginning of the phenomenon. The topics considered in the surveys are numerous and range from the scope of immigration and its dynamics to the idea of foreigners as a presence among Italians, and also include many others, such as intercultural contacts, the relationship between immigration and criminality, economic impact, and migration policy. This paper will examine some of these issues trying to emphasise a diachronic reading of the results. In particular, we will consider in more detail the opinions related to the entry process of people coming from other

1 The first three surveys were conducted on samples of over three stages of stratification of the primary units. In all three cases, the primary units constituted municipalities, the secondary units constituted electoral divisions and the third units constituted individuals aged 18-49 for the 1987-88 survey, 18-64 for the 1991 survey, and 20-49 for the 1997 survey. The interviews comprised 1,500 individuals in 1997-88, 1,800 (of which 1,270 were aged 18-49) in 1991, and 1,519 in 1997. In the 2002 survey, using the Computer Assisted Telephone Interviewing (CATI) technique, 3,000 people aged 20-69 (1908 were aged 20-49) were interviewed; the sample was representative of the Italian population by sex, age group and geographic distribution. For reasons of comparability, the comparison data related to the 1991 and 2002 surveys are not compared to the total number of interviews, but solely to those carried out on the population aged 18-49 in the first case and $20-49$ in the second. For this reason, there may be differences with the data compared with the totality of the samples. 
countries, the role of immigrants in the national labour market, and the policies for addressing the phenomenon. The nature of the paper is mainly empirical, with the aim of offering a general overview of the changes that have characterised Italians' opinions in the course of fifteen years of crucial developments in foreign immigration.

\section{Italian society facing immigration: evaluations, perceptions and fears}

In 2002, $60 \%$ of those interviewed felt that there were too many immigrants living in Italy, a value practically analogous to the 1997 survey (Table 1). With regard to this question, the differences between the last two surveys are quite modest, especially considering that the slight increase in the responses of "neither too many nor few" and "few" are connected to a decrease in the "I don't know" response, which is, with all probability, a consequence of the different type of survey that determined an appreciable reduction of such modality in several questions. On the contrary, the changes in the previous surveys were of a completely different intensity. The response of "too many" did in fact shoot up from $49.7 \%$ in $1987-88$ to $71.3 \%$ in 1991 , an increase of more than 21 percentage points, and went down to $60.9 \%$ in the 1997 survey. This increase was due to a strong reduction in the response of "not too many nor few", which declined by almost 14 points, and the "I don't know" response, which decreased from 12.8 to $5.3 \%$. The following decrease in "too many" is almost completely attributable to the growth of the intermediate modality by 10 points, as the uncertain area remains unchanged as a whole in both of the surveys conducted in the 1990's.

Table 1. Opinions about the number of foreigners living in Italy (\%)

\begin{tabular}{lcrrr}
\hline Opinion & $1987-88$ & 1991 & 1997 & 2002 \\
\hline Too many & 49,7 & 71,3 & 60,9 & 60,0 \\
Neither too many nor few & 35,7 & 22 & 32,1 & 35,3 \\
Few & 1,7 & 1,4 & 1,3 & 2,9 \\
Don't know & 12,8 & 5,3 & 5,7 & 1,8 \\
\hline Total & 100,0 & 100,0 & 100,0 & 100,0 \\
\hline
\end{tabular}

Source: IRP and IRPPS data.

These important changes allow us nevertheless to discern the rather noticeable transformation in the climate towards immigrants and immigration from one survey to the next. It should not be forgotten that the 1991 survey was carried out between two huge exoduses of Albanians to the Puglia coastline that dramatically placed the question of immigration at the centre of public attention. Another interesting point to consider is the substantial independence between the opinions and the actual dimensions of the phenomenon, which is a result already indicated by previous international comparisons (Bonifazi and Kamaras 1998). 
The education level of interviewees has always been a key variable in the determination of opinions towards immigration, and its role probably emerges with greater clarity in the case of this question (Figure 1). An increase in the level of education has always been associated with a lower percentage of the opinion that there are too many immigrants. In particular, the gap between those with only basic education and those with a university degree increased from 15 percentage points in the first survey to 21 in 1991, and to 44 in 1997 and 42 in the latest survey. The increase in 1991 in the figures registered for this modality for all educational levels is very clear, with the result that also among persons with a university degree, the percentage who felt there were "too many" largely prevailed (60\%). In the two subsequent surveys, on the other hand, the main element appears to be the increase in the gap between the four groups under consideration, always with a clearer separation between university graduates and other education levels. In 2002, for example, the difference between university and high school graduates was practically equal to the gap between the two extremes fifteen years earlier. University graduates are also the only group where the "neither too many nor few" option won the majority both in 1997 and 2002, reaching $46 \%$ and $56.1 \%$ of the total, respectively. The periods we examined seem to have been characterised by a tendency towards polarization of positions, especially with regard to the most highly educated population layer, with a substantial swelling of the gap that separates the highest figure from the lowest, and a stabilization of the differences in the last two surveys.

Another general characteristic where our surveys allow a comparison are the opinions of the interviewees on the presence of immigrants as a positive element of cultural

Figure 1. "Too many foreigners" according to education level

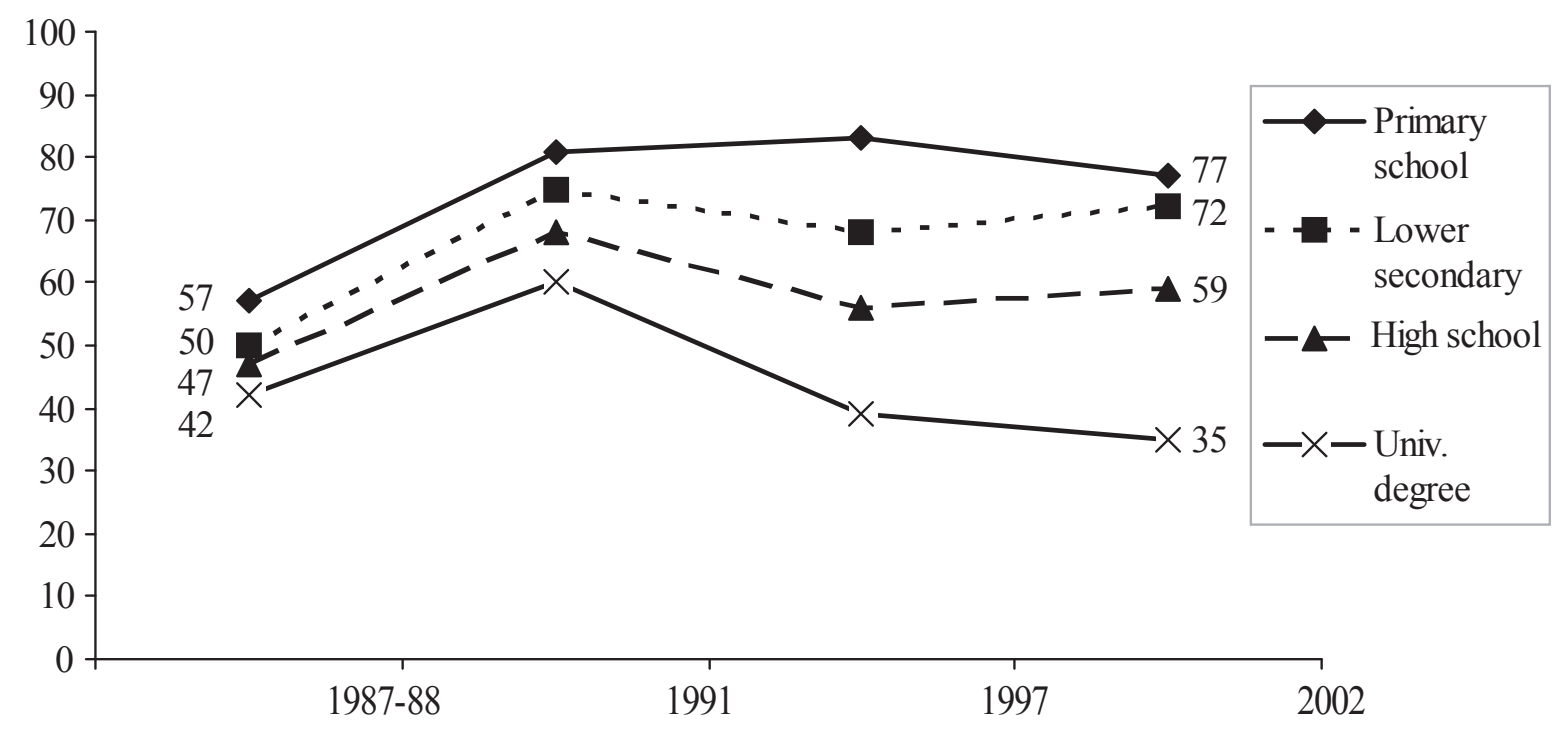

Source: IRP and IRPPS data. 
exchange (Table 2). The shift in attitudes with regard to this question over the two last surveys appears rather remarkable: in five years, the share of Italians who agreed with the assertion in fact shifted from 41.7 to $62.5 \%$, an increase of more than 20 percentage points. The result is even more remarkable, if we consider that until then, the highest level of agreement only reached $48.5 \%$ in the first survey, which was carried out at a time when the prevailing predisposition towards immigration and immigrants within Italian society seemed good. In the time in question, on the other hand, Italians had changed their position little on the relationship between criminality and immigration. The people who agreed with the idea that the increase in immigration has helped the spread of terrorism and criminality had always been in the majority, with the exception of the first survey. In 2002, the gap between agreeing and disagreeing had increased slightly in respect to the previous surveys, but only just exceeded 5 percentage points. Overall, no major differences seem to emerge, especially taking into account the importance of public discussion concerning the relationship between immigration and criminality or terrorism in Italy, where certain events have been ascribed more or less justly to foreign citizens, and taking into account the attacks of the $11^{\text {th }}$ of September. Between 1997 and 2002 a decrease of almost 9 percentage points was recorded for those who think that Italy belongs to Italians and that there is no room for immigrants. The $12.8 \%$ of respondents in 2002 favourably inclined towards this extreme position represent the lowest value to emerge in our surveys.

One last facet in the overall evaluation of the immigration phenomenon that is comparable with the previous surveys is the question about perceived problems in the event of having an Arab family as neighbours (Table 3). In 2002, the number of those who admitted to having a problem with such a situation remained practically unchanged from the 1997 survey. The proportion of those in the sample who said they would have no problems with it had, on the other hand, increased by 9 points, reaching $82 \%$ of the total, thanks to a strong decrease in the response of "I don't know". Far more relevant are the changes that occurred between the first survey and the one in 1997: in $1987-88,14.7 \%$ of Italians said they would have many problems with an Arab family as a neighbour, $14.5 \%$ said they would have some problems, and $64.3 \%$ said they would have no problem.

In the 2002 survey, we tried to verify the intensity of perceived problems in the event that a son or daughter should choose someone of the same age and of Albanian origin as an acquaintance, friend or $\operatorname{partner}^{2}$ (Figure 2). In the first two cases the replies were rather similar: "many problems" exceeded in both cases just $7 \%$ of the total. Those who would have "some problems" went from 16.3 to $18.3 \%$, those who would have "no problems" were 72.3 and 70.5\%, whereas the "I don't know" responses accounted

$267.6 \%$ of the sample had children at the time of the survey. 
for $4 \%$. The situation changed radically when the suggested scenario was a son's or daughter's engagement: "many problems" more than doubled, rising to $18.7 \%$, those who would have "some problems" climbed to $22 \%$, those with "no problems" drastically decreased to $53.1 \%$, and the "I don't know" category increased to $6.2 \%$.

Table 2. Some opinions toward immigration

\begin{tabular}{lrccc}
\hline Question & Survey & Agree & Disagree & Don't know \\
\hline "Immigration is a good way & $1987-88$ & 48,5 & 45,5 & 6,0 \\
to have contact with other & 1991 & 35,5 & 61,9 & 2,6 \\
cultures" & 1997 & 41,7 & 55,2 & 3,1 \\
& 2002 & 62,5 & 36,8 & 0,6 \\
\hline "An increase in the number of & $1987-88$ & 46,7 & 48,9 & 4,4 \\
immigrants leads to the spread & 1991 & 50,7 & 47,1 & 2,1 \\
of crime and terrorism" & 1997 & 49,7 & 46,5 & 3,8 \\
& 2002 & 52,3 & 46,9 & 0,8 \\
\hline "Italy is for Italians, no place & $1987-88$ & 15,8 & 79,5 & 4,7 \\
here for immigrants" & 1997 & 21,6 & 75,9 & 2,4 \\
& 2002 & 12,8 & 86,7 & 0,5 \\
\hline
\end{tabular}

Source: IRP and IRPPS data.

Table 3. Problems arising from having an Arab family as a neighbour (\%)

\begin{tabular}{lccc}
\hline Degree of problems & $1987-88$ & 1997 & 2002 \\
\hline Many & 14,7 & 4,5 & 4,0 \\
Some & 14,5 & 11,9 & 12,2 \\
No problems & 64,3 & 73,0 & 82,0 \\
Don't know & 6,6 & 10,6 & 1,8 \\
\hline Total & 100,0 & 100,0 & 100,0 \\
\hline
\end{tabular}

Source: IRP and IRPPS data.

Considering the most recent survey, education level appeared to be a key variable in defining the opinions of the interviewees, with levels of preoccupation and refusal clearly increasing with a decline in the level of education. Interviewees with a basic level of education or below, present, therefore, some percentages that are more than double those of university graduates in believing that there are "too many" immigrants (75.9 and 37.8\%) and among those who wholly disagreed with the claim that immigration could offer positive cultural exchange (23 and 10.9\%). The difference became three-fold when considering those who strongly agreed that there was a relationship between the growth of immigration and increase in criminality (38.5 and $11.1 \%)$. The increase is four times greater for the response to "having an immigrant family as neighbours will lead to many problems" (9.7 and 2.1\%). The difference was 
Figure 2. Problems as result of having an Albanian boy or girl as an acquaintance, friend, partner of one's own son/daughter, 2002 (\%)

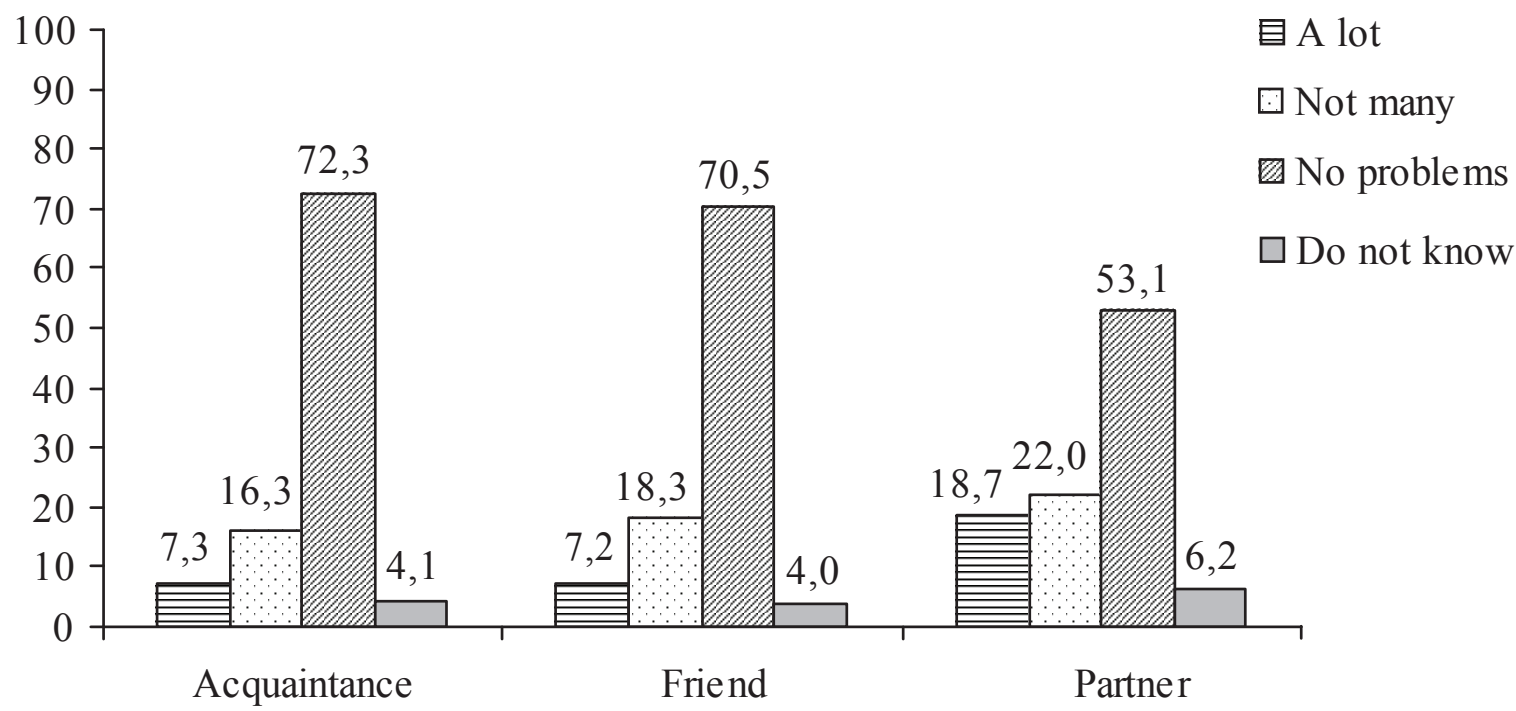

Source: IRPPS data.

even six-fold in the case of the claim that "Italy is only for Italians" (13.9 and 2.3\%). The only case in which the proportions of the respondents with lower education were not at least double those of university graduates was regarding the issue of having "many problems" with a daughter choosing an Albanian partner - with values of 23 and $13.8 \%$, respectively.

Fears regarding immigration increased with age, with the exception of 30-year-olds, who almost systematically present values of refusal superior to the 20-year-olds and the 40-year-olds (Bonifazi 2005). Differences between the youngest and oldest groups, represented in our sample by 20 -year-olds and 60 -year-olds, were sometimes remarkable. For example, for those who strongly agreed that there was a relationship between criminality and immigration, the older group was twice as likely as the younger group to hold that belief (33.6 and 16.8\%). Geographical differences were less relevant, even though in the south we registered the highest values for the opinion that there are "too many" foreigners or that "Italy is for Italians and there is no room for foreigners". Conversely, in terms of immigration's relationship with criminality and the problems with having immigrants as neighbours or as the partners of the respondents' children, the north-east of the country expressed the most fear. Teachers and students had the highest levels of receptiveness, whereas the greatest concern over general immigration issues occurred among housewives, retirees, workers and the unemployed. Thus, $43.1 \%$ of teachers and $48.4 \%$ of students thought that there were "too many" immigrants, whereas $65.6 \%$ of retirees, $69.3 \%$ of the unemployed, $71.2 \%$ of workers, and $74.6 \%$ of housewives thought so. 
The data related to the political affiliation of the interviewees appears to be aligned with the positions of the political parties. In this sense, it is probable that the $44.3 \%$ in the sample that didn't know its political affiliation (or didn't want to place itself in a political position) contributed to making the results even more evident and clear following this particular subdivision of the population. It is interesting to point out that, contrary to what one might think, those who declared that they belonged to the centreleft nearly always showed lower levels of concern than those who affiliated themselves with the left. In any case, the percentages increased from left to right. For instance, the percentage of those who thought there were too many immigrants increased from 46.6 to $77.8 \%$, those who found nothing positive in the cultural exchange brought by immigration went from $11.5 \%$ on the left to $29.1 \%$ on the right. The proportion of those with a strong belief in a direct relationship between immigration and criminality was 19 and $40.7 \%$, respectively. It is interesting to note that the lowest levels of fear towards immigration were almost always found among those who considered religion unimportant, whereas the highest levels of fear often belonged to those who considered religion very important (Bonifazi 2005).

\section{Immigrants and work}

The changes that the latest survey has shown in Italians' opinions on the role of immigration in the national labour market are particularly interesting (Table 4). The question regarding the need for immigrants to do the jobs Italians no longer want to do presented the most remarkable new finding. The proportion of interviewees who agreed with the idea of immigration as substitution for the native labour force in socially undesirable jobs was $60.7 \%$. This figure is almost three times greater than in the 1997 survey. Simultaneously, the proportion of those who disagreed dropped from 73.5 to $38.5 \%$. This shift is even more significant when taking into account that in the previous surveys, a clear majority disagreed with the hypothesis of the complementary function of immigration. It is probable that the impression that immigrants have a function in substituting Italians in many jobs that have been abandoned by the national workforce is now widespread in Italian public opinion. This hypothesis is largely confirmed by the results of the question concerning the competitive role of the foreign workforce. In this case, in fact, the percentage of interviewees who agreed with the statement that "immigrants steal work from Italians" decreased to $23.7 \%$, whereas the proportion of those who disagreed increased to $75.7 \%$. The temporal trend for this question is more regular than for the preceding question; it is characterised in the four surveys by a continuous decrease in the percentages of those who agree and an increase of those who disagree. The overall result is, for the first time, the merging of a coherent view of immigration as a complementary element to the local labour force, since in the previous three surveys, the majority of Italians simultaneously disagreed with this 
Table 4. Immigrants in the labour market

\begin{tabular}{lcccc}
\hline Question & Survey & Agree & Disagree & Don't know \\
\hline "Immigrants are necessary to do & $1987-88$ & 20,1 & 77,1 & 2,4 \\
the jobs that Italians no longer & 1991 & 35,2 & 63,8 & 1,1 \\
want to do" & 1997 & 24,2 & 73,5 & 2,3 \\
& 2002 & 60,7 & 38,5 & 0,8 \\
\hline "They 'steal' work from Italians" & $1987-88$ & 46,8 & 50,4 & 2,8 \\
& 1991 & 43,3 & 54,1 & 2,5 \\
& 1997 & 30,5 & 66,8 & 2,8 \\
& 2002 & 23,7 & 75,7 & 0,6 \\
\hline
\end{tabular}

Source: IRP and IRPPS data.

view of the phenomenon and with the opposite position, where foreigners were seen as being in competition with the native population.

In the 2002 survey, a great majority of Italians (84.6\%) reported living in areas where foreign workers were present. The presence of immigrants appears to involve a large part of the nation's territory, as is also shown by data regarding the geographical distribution of immigration. Thirty-six percent of interviewees who replied positively to this question saw the presence of immigrant workers solely as an advantage for the local economy, $45.4 \%$ saw, in their entry into the structures of production, a source both of advantages and disadvantages, whereas $11.8 \%$ saw only disadvantages. A similar question addressed the national economy and was posed to the $15 \%$ of the sample, who reported living in a part of the country where there were no foreign workers present. The differences in the responses to these two questions are worthy of note (Figure 3). In the latter case, compared with the former, the percentage of those who only saw advantages more than halved, those who only saw disadvantages almost doubled, and the intermediate category increased by ten points. The impression is that those who live in areas with foreign workers tend to evaluate their economic impact in a more positive way.

The highest percentage of interviewees who saw only advantages for the local economy occurred among those who placed themselves politically to the left $(45.4 \%)$ or the centre-left (43.7\%), among university graduates $(43.1 \%)$, 40-year-olds (41.8\%), residents of the north-east (41.5\%), retirees (41.3\%), and teachers (40.1\%). Apart from the groups that were generally more positively disposed towards immigration, high levels were also registered in north-eastern Italy and among retirees - an interesting result, since it points out that, within Italian society, certain positive evaluations are developing among certain population groups towards some of immigration's effects and an overcoming of previous fears. On the other extreme, besides housewives (29.6\%) and interviewees on the political right $(25.5 \%)$, were those residing in central Italy 
Figure 3. Positive and negative effects of foreign workers on local and national economy $(a), 2002$ (\%)

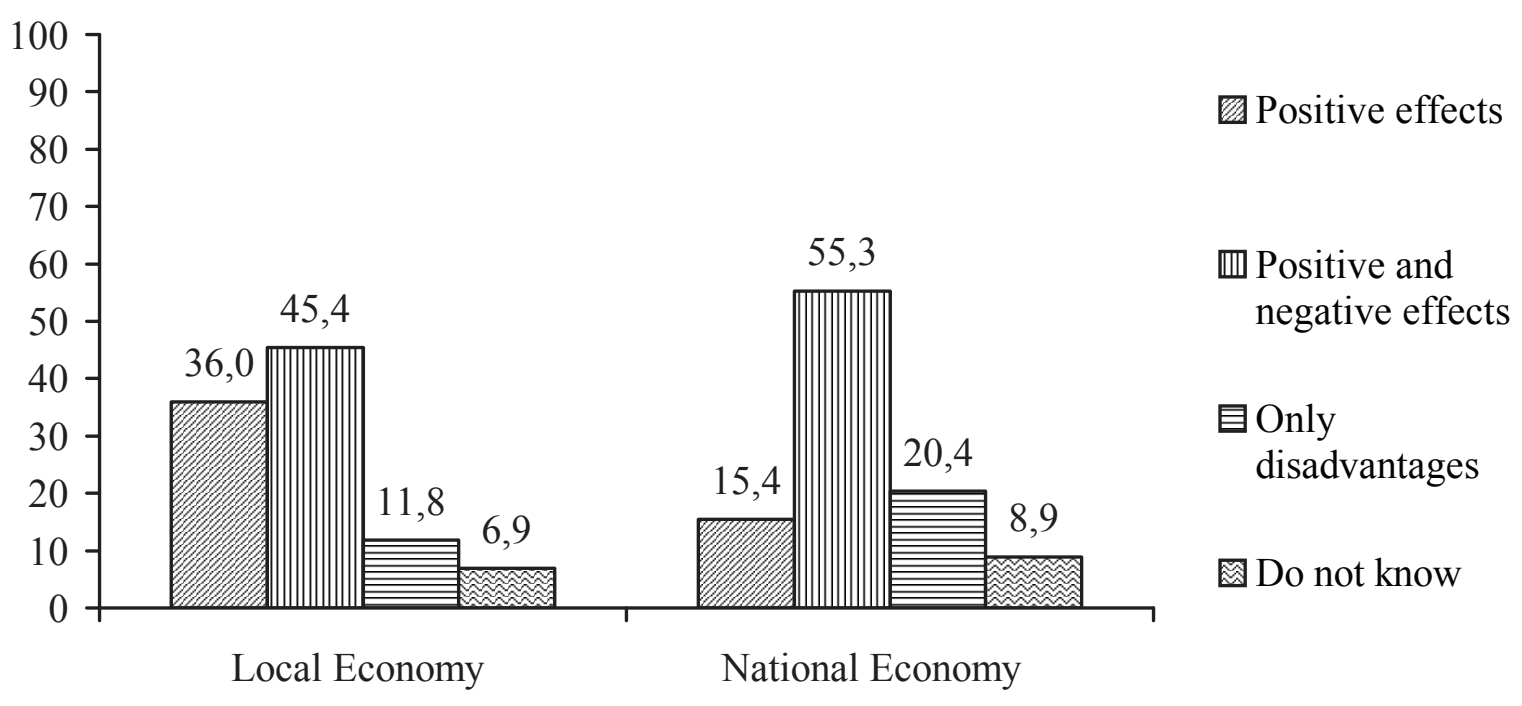

(a) Only those whose cities have a presence of foreign workers answered the first question.

Source: IRPPS data.

(32.8\%), the south (33.4\%), in towns with more than 500,000 inhabitants (29.3\%), 20year-olds (31.7\%), and the unemployed (24.4\%). The fact that the unemployed have the low percentage of those who see immigration as bringing only advantages for the local economy is no surprise. The positive results of immigration also appeared to be less perceived by those living in big cities.

Thirty-six percent of interviewees said that the economic sector with the largest number of immigrant workers was agriculture, followed by domestic work $(22.1 \%)$, industry (15.4\%), construction (14.9\%), commerce (5.1\%), and restaurants (3\%) (Figure 4). As a general rule, all major sectors with immigrant workers were considered, even though the high percentage assigned to agriculture seems too high to represent reality. The significant geographical differences strongly influenced the results. For example, those who indicated agriculture accounted for up to $53.5 \%$ of the sample from the south, but the percentage of respondents who chose the same response is only $24.5 \%$ in the north-west and north-east. As for domestic work, the differences are less marked. They are greater for industry, where the percentage fluctuates from $6.2 \%$ in the south to $31.8 \%$ in the north-east. As for construction, the maximum percentage came from the north-west $(22.8 \%)$ and the lowest in the south (4.5\%). The differences in the responses evidently reflect the different migratory models that characterise the country and the presence of differing factors of attraction for migrant workers amid the country's differing realities.

Over three-fourths of Italians (77.8\%) thought that the majority of immigrants work in illegal conditions. This viewpoint peaked at $93.1 \%$ among the unemployed, whereas 
Figure 4. Main employment sector of immigrants, 2002 (\%)

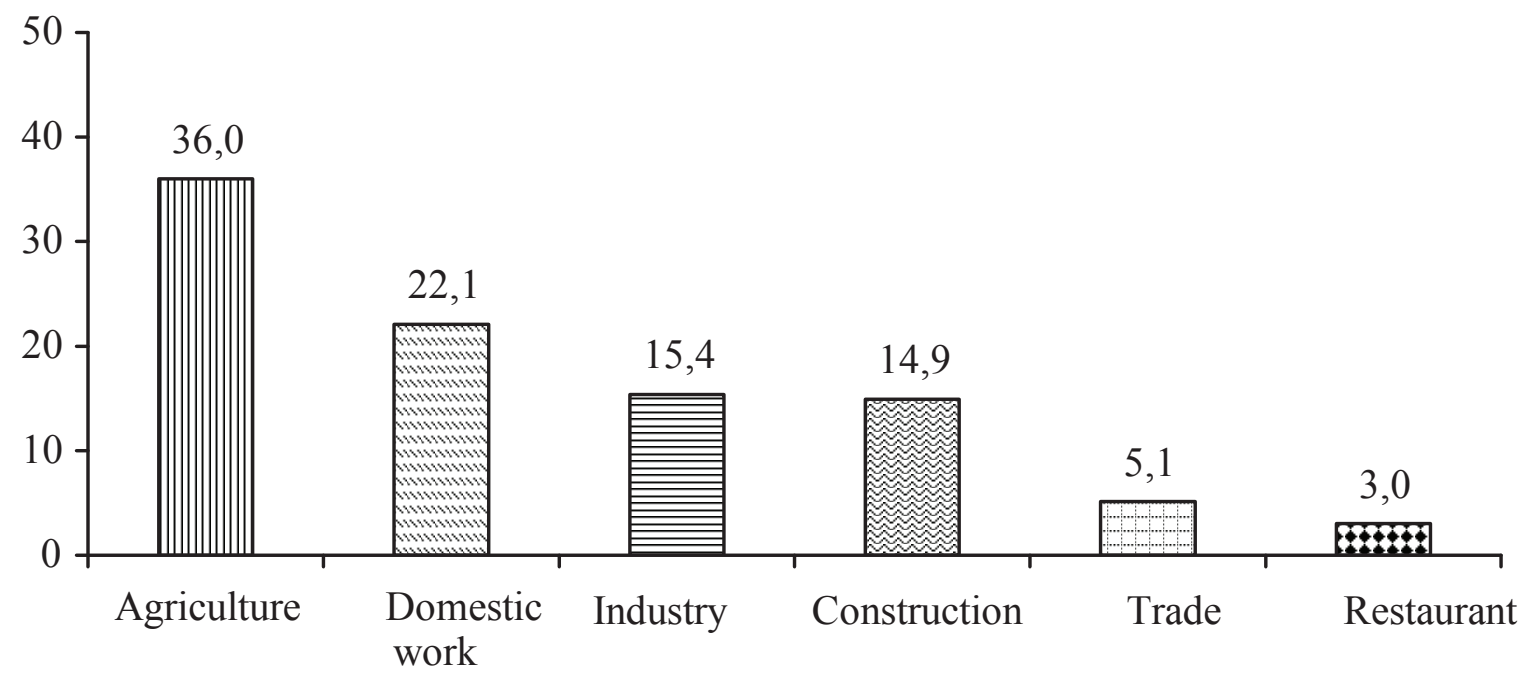

Source: IRPPS data.

only $15.4 \%$ of the interviewees as a whole believed that immigrants mainly work with regular work contracts. The geographical differences were noticeable: the figures were $86.3 \%$ for southerners and $85.7 \%$ for people in cities with over 500,000 inhabitants. They declined to $65.9 \%$ in the north-east and approached the average value in towns with fewer than 5,000 inhabitants (74.5\%), in the north-west (75.2\%), and in central Italy (77.9\%). These figures reflect and describe with a certain coherence three different immigration models that are present in Italy. The first model is characteristic of the south, where entry into the labour market mainly takes place through agricultural and domestic sectors, often with no work contract, and also as a result of the strong presence of the black market in this part of the country. The second model is that of the great metropolitan areas, with workers flowing mainly to the construction and unskilled service sector, where working without a regular contract is, if not the rule, certainly rather widespread. The last model is that of north-eastern Italy, where economic and demographic factors have contributed to easing the entry of immigrants into the industrial sector and where, with all probability, working conditions are more regular than in other parts of the country.

In this regard it is interesting to note that the highest rates of interviewees who strongly agreed that immigrants are necessary to do the work that Italians do not want to do occurred among the 60-year-olds (35.7\%), shop keepers and retirees (both at 35.5\%), and in the north-east (34.5\%). The lowest percentages, on the other hand, were recorded among the unemployed (20.8\%), in the south (23.3\%), and among interviewees who declared themselves to belong to the center-right or right ( 25 and $24.7 \%$ ). These results substantially coincide with certain important characteristics of foreign immigration in Italy. The highest level of strong agreement regarding the complementary function of immigration in the workforce is, in fact, recorded among 60-year-olds, the group 
closest to experiencing the actual indispensability of foreigners in elder care; whereas the diverse characteristics that immigration has manifested at the regional level allows us to understand the reasons that have led the north-eastern area to occupy one extreme on the scale and the south another. The reasons that led the unemployed to express the lowest levels of strong agreement on this statement are equally clear.

\section{Immigration policies}

The number of Italians who think the government should limit the number of foreign workers, though still a wide majority in representing three-quarters of the total, decreased by more than 13 percentage points between 1991 and 2002 (Table 5). This is the lowest figure registered in our surveys, but it confirms the existence of a large majority in favour of the government's central role in dealing with migratory flows. Even the percentage of those in favour of allowing voting rights to immigrants in municipal elections following several years of residence diminished slightly in 2002, compared with the 1997 survey. In that case, the percentage of people in agreement declined from 62.3 to $58.6 \%$; still the majority, but showing a change of trend compared with the previous decade, during which the figure had increased from the first survey's level of $45.5 \%$. It is interesting, for such a key issue in immigration policy, that the increase in favourable attitudes occurred practically across all population groups, including those that generally express the highest concern about immigration (Table 6). The 2002 survey confirms the prevalence of those in favour of government control among the major population groups, but within the framework of an almost-acrossthe-board decline in the figures, even though those in favor rose in some categories that had shown more caution in 1997.

Irregular immigration in its diverse forms certainly represents one of the points on which, more frequently and in a livelier manner, the debate on the migration question focuses. It is also one of the points on which, with more evidence, the gap between the declared political objectives and the actual dynamics of immigration has manifested. On the one hand, the interventions are aimed at drastically reducing if not completely eliminating this area of irregularity, while on the other hand, the push forces in emigration areas and the pull forces in the economies of the receiving countries work to feed this component of migration largely beyond whatever political goals that may have been set. The results of the 2002 survey showed that $82 \%$ of Italians were in favour of the legalization of immigrants without a permit to stay, from the moment they find a job (Figure 5). The interviewees were also mainly in favour of the immediate expulsion of those who are in the country illegally, even though the percentage is 30 points lower. The number of those in favour and those against are much closer in this case. As a general rule, these responses, and especially the difference between the percentages for the two questions, tell us that there is a need to control immigration and all 
Table 5. Opinions on migration policies

\begin{tabular}{lcccc}
\hline Question & Survey & Agree & Disagree & Don't know \\
\hline "The number of foreign workers should be & 1991 & 87,8 & 10,0 & 2,2 \\
defined by the government" & 1997 & 80,1 & 16,3 & 3,5 \\
& 2002 & 74,5 & 22,7 & 2,8 \\
\hline "All foreigners should be allowed to vote in & $1987-88$ & 45,5 & 45,8 & 8,6 \\
local elections after some years of residence" & 1991 & 51,2 & 40,5 & 8,3 \\
& 1997 & 62,3 & 30,2 & 7,5 \\
& 2002 & 58,6 & 36,9 & 4,4 \\
\hline
\end{tabular}

Source: IRP and IRPPS data.

Table 6. Favourable attitude towards voting rights

\begin{tabular}{lcccc}
\hline Group & $1987-88$ & 1991 & 1997 & 2002 \\
\hline Male & 44,1 & 53,6 & 61,2 & 57,8 \\
Female & 47,0 & 48,8 & 63,4 & 59,5 \\
$18-29$ & 46,3 & 50,0 & 56,9 & 57,7 \\
$40-49$ & 42,5 & 49,2 & 65,5 & 60,4 \\
Primary school & 36,7 & 42,2 & 50,9 & 56,9 \\
University graduate & 56,0 & 56,0 & 72,3 & 64,5 \\
North - West & 52,3 & 55,0 & 64,2 & 64,0 \\
South & 37,6 & 45,0 & 59,5 & 56,4 \\
Employed & 44,7 & 51,5 & 64,7 & 59,1 \\
Unemployed & 45,1 & 47,1 & 52,7 & 57,2 \\
Housewives & 44,0 & 45,9 & 60,9 & 55,2 \\
Students & 53,2 & 58,6 & 64,7 & 65,2 \\
\hline
\end{tabular}

Source: IRP and IRPPS data.

its irregular forms, but that the control should be flexible and allow the legalization of illegal immigrants who have jobs.

The figures for those who strongly agreed that immigrants should be legalised when they find work do not always follow the path that one would expect. For instance, they increase with age, showing the most favourable positions among 50-year-olds and 60year-olds; they are higher in the north and lower in the centre-south; do not show the usual differences by education level or profession; and the differences based on political affiliation are less predictable than in the case of other political measures. The proposition of dealing with the legalization issue in a flexible manner seems to have gathered much favour in a wider cross-section of the population than just the group that generally responds most favourably to immigration questions. What emerges is a geography that, at least in certain aspects, is different from the one that has generally characterised the 
survey results. Among the categories that show the highest levels of agreement with this political option we find, apart from teachers (55.1\%), also shop keepers (51.8\%), retirees (48.8), 50-year-olds (48.2\%), inhabitants of the north-west (47.3\%), and 60-year-olds $(46.9 \%)$. Whereas the smallest share of those in favour, apart from respondents affiliated with the political right or centre-right - the only categories in which the modality declines below $40 \%$ - occurs among those who consider religion unimportant (41.6\%), students (41.4\%), inhabitants of the south (40.9\%), and 30-year-olds (40.6\%).

In terms of the immediate expulsion of illegal immigrants, even in the absence of offences, the responses as a whole tend, instead, to follow the geography of acceptance and refusal that the results of our survey have indicated on more than one occasion. Those strongly in favour of immediate expulsion tend to increase with age. Among our interviewees, they occur at higher rates in the north-east (35.9\%) and lower rates in the south $(28.2 \%)$, increase as education levels decrease, and are lower among students (19.4\%) and higher among retirees (37.9\%) (Bonifazi 2005). The most appreciable differences exist when taking into consideration political affiliation, with a gap between the $20.6 \%$ for those on the centre-left and $52.4 \%$ for those on the right; it is also interesting to note that, from this point of view, teachers $(31.7 \%)$, one of the most favouraubly inclined groups towards immigration, do not stand out very much from the rest of the population and present a figure that is practically equal to the overall average (32\%). In 2002, $71.7 \%$ of Italians stated that they felt favourably toward allowing citizenship after five years of residency, which would represent a halving

Figure 5. Opinions on some immigration policies, 2002 (\%)

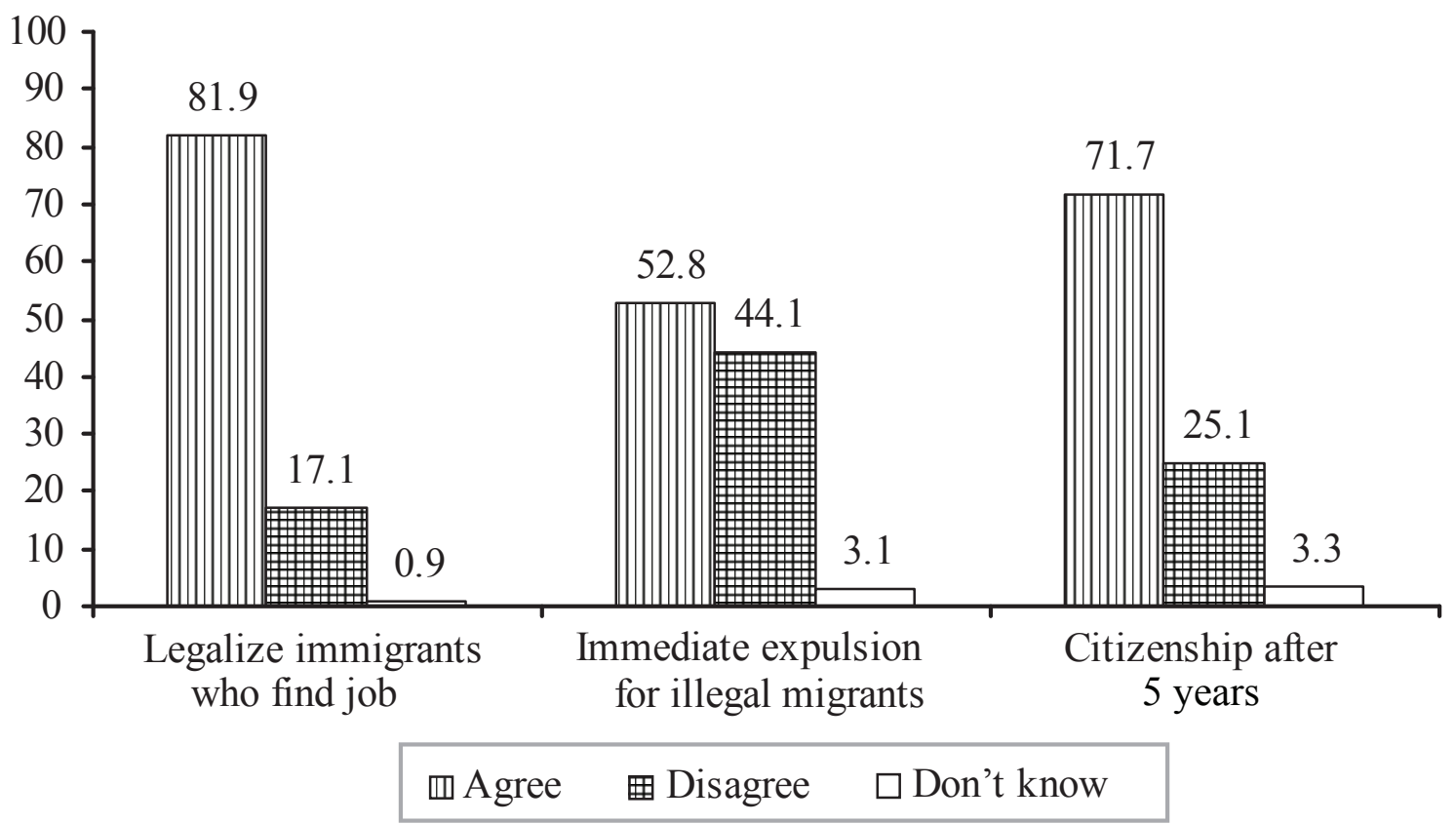

Source: IRPPS data. 
of the current limit (Figure 5). Paradoxically, this figure is a good 11 points higher than the one related to the question of allowing immigrants to vote in local elections, a measure that would substantially fall in case the criteria for allowing citizenship were to be enlarged. Deviating in a rather consistent way from the average profile, in which $32.6 \%$ of the interviewees are in total agreement with this hypothesis, are the respondents mostly in favour, especially those affiliated with the left $(41.9 \%)$ or centre-left (37.4\%), teachers (44.3\%), those who consider religion unimportant (37.6\%), and students (36.6\%); amongst the least favourably inclined, on the other hand, are the interviewees on the centre-right (27.4\%) and right (27.3\%), shop keepers (29.1\%), those who consider religion very important (29.6\%), and housewives (29.9\%). A clear association between political affiliation and the positions taken is apparent, but it must be emphasised that interest in this issue, which may indicate a very important step in the evolution of the Italian immigration model, is at a very high level, even among the least favourably inclined groups.

\section{Conclusions}

As a whole, the 2002 survey findings seem to confirm the trend that began to take shape in 1997 on the formation of thoughtful opinions, as the result of an evaluation of the costs and benefits of immigration. In certain respects, the differences between the two surveys are minor and in some cases, confirm the specific opening and closing positions toward immigration that have emerged since the first survey. The geography of acceptance and refusal has, with the 2002 survey, seen the opening of new positions, opinions linked to different characteristics that immigration presents at the regional level, or referred to the different interests within the population.

A very interesting aspect was the increase of almost 20 percentage points compared with 1997 , in responses that reflected agreement with immigration as a positive cultural communication factor, a shift that after fifteen years brought those in favour of this position back into the majority. The nearly 9-point decline in those in favour of the idea that "Italy belongs to Italians and there is no room for immigrants" is headed in the same direction; whereas the overall stability in the positions regarding the relationship between immigration and criminality confirms that these fears represent a strong presence and seem as a whole to be impermeable to external influences, there is the probable exception of surveys carried out close to episodes of particular gravity. As regards the overall evaluation of the immigration phenomenon, the results seem to be largely in line with the findings of the previous surveys. A point that deserves some attention is the difference in the levels of fear between the south and north-east: in the south, people are more worried about there being too many foreigners, in the north-east, they are concerned about criminality and have greater apprehension toward living in close proximity with immigrants. In 2002, Italians seemed, for the first time, to have reached a clear and coherent vision of the role 
that immigration plays in the national labour market. Our interviewees expressed the opinion that immigrants were arriving in Italy as substitutes for locals who no longer want to work in certain jobs, not to steal their jobs. This is an important finding, because the preceding surveys showed contradictory positions. A clearer position on this issue could contribute to a better definition of the role of immigration within Italian society as a whole. It is also interesting, in certain questions, to note the formation of differing positions among different population groups, resulting from the characteristics that immigration presents in a particular area and the advantages and disadvantages that this may cause for a particular group. This dynamic can help to move the political discussion on immigration toward a more rational level.

Overall, Italians confirmed that they are in favour of central authorities controlling immigration and allowing immigrants the right to vote in local elections, and that they are also in favour of halving the necessary residence period for being eligible for citizenship. Among the interviewees, $82 \%$ were also in favour of legalising illegal immigrants if they find a job, while 52.8\% agreed with their immediate expulsion. A demand that central authorities control the phenomenon is clear, but even clearer is the demand that immigration be addressed with flexibility and pragmatism, with important and decisive concessions at the level of civil rights. To sum up, our surveys seem to indicate a progressive acceptance of immigration in the public opinion, with a clear appeal for control and management of immigration by government authorities, but also with important openings on a civil rights level and in the overall recognition of this new reality in the country.

The findings of our surveys seem to confirm the complexity of reasons behind people's attitudes towards immigration. Our questionnaires have always been devoted to collecting information on opinions towards migration trends and immigration policies, and not to inquire into the reasons for ethnic prejudice. Nevertheless, this makes our results better suited to highlight the socio-economic reasons than cultural factors behind people's fears towards newcomers, while cultural variables (religiosity, political orientation, etc.) have often been demonstrated to be influential in determining opinions. Education level is a cultural variable but also a strict proxy of socio-economic status and it emerges as one of the most important determinants of opinions and attitudes. By and large, the attitudes of Italians appear to be the result of different and sometimes competing factors, with the last survey showing the importance of the respondents' positions directly related to an evaluation of the cost-benefit of immigration. From a comparative perspective, the most interesting result is probably the confirmation that attitudes are not directly related to the size of immigration. In reality, the worst attitudes in Italy were recorded in the 1991 survey, whereas the considerable growth in immigration during the nineties has seen an increase of more receptive positions - a result that could be useful to other new immigration countries in Europe. 


\section{References}

Bauer, T., M. Lofstrom and K.F. Zimmermann. 2000. Immigration policy, assimilation of immigrants, and natives' sentiments towards immigrants: evidence from 12 OECD countries, Swedish Economic Policy Review 7(2):11-53.

Bonifazi, Corrado. 1991. Gli italiani e l'immigrazione straniera. In: Crescita zero. Le opinioni degli italiani in un'indagine dell'Istituto di ricerche sulla popolazione, edited by Rossella Palomba, pp. 17-72. Scandicci: La Nuova Italia.

Bonifazi, Corrado. 1992. Italian attitudes and opinions towards foreign migrants and migration policies. Studi emigrazione 29(105):21-42.

Bonifazi, Corrado. 1995. Migration policy acceptance in Italy. In: Contributions of Italian scholars. European Population Conference, Milan 4-8 September 1995, pp. 251-265. Roma: Irp-Cnr.

Bonifazi, Corrado. 1996. Gli italiani e l'immigrazione straniera. In: Bambini, anziani e immigrati. Le opinioni degli italiani in un'indagine dell'Istituto di ricerche sulla popolazione, edited by Corrado Bonifazi, Adele Menniti and Rosella Palomba, pp. 135-185. Scandicci: La Nuova Italia.

Bonifazi, Corrado. 2005. Accettazione e rifiuto nelle opinioni degli italiani. In: L'incidenza economica dell'immigrazione, edited by Massimo Livi Bacci, pp. 87-117. Torino: Giappichelli.

Bonifazi, Corrado and Loredana Cerbara. 1999. Gli immigrati stranieri: valutazioni, conoscenze e giudizi degli italiani. Studi emigrazione 36(133):3-38.

Bonifazi, Corrado and Maria G. Caruso. 2000. Atteggiamenti ed opinioni degli italiani nei confronti della presenza straniera. In: Il bacino mediterraneo tra emigrazione ed immigrazione, edited by Luigi Di Comite and Gabriele Di Comite, pp. 11-35. Bari: Cacucci.

Bonifazi, Corrado and Ferenc Kamaras. 1998. Perceptions of population issues and their consequences: scholars, governments, and public opinions. In: Population, Family, and Welfare. A Comparative Survey of European Attitudes, Volume II, edited by Rossella Palomba and Hein Moors, pp. 1-33. Oxford: Clarendon Press.

Commissione per le politiche di integrazione degli immigrati. 1999. Sondaggio ISPO - Commissione integrazione, settembre - ottobre 1999. L'atteggiamento degli italiani nei confronti degli immigrati. Working Paper, No. 3. Roma, Dipartimento per gli Affari Sociali.

Commissione per le politiche di integrazione degli immigrati. 2000. Sondaggio ISPO - Commissione integrazione, settembre - ottobre 2000. L'atteggiamento degli italiani nei confronti degli immigrati. Working Paper, No. 11. Roma, Dipartimento per gli Affari Sociali.

Diamanti, Ilvo (editor). 2001. Immigrazione e cittadinanza in Europa. Seconda indagine sugli atteggiamenti dei cittadini in otto Paesi Europei. Appunti preliminari sui risultati. Quaderni Fne, Collana osservatori, No. 3.

Diamanti, Ilvo and Fabio Bordignon (editors). 2005. Immigrazione e cittadinanza in Europa. Orientamenti e atteggiamenti dei cittadini europei. Primi risultati. Quaderni Fne, Collana osservatori, No. 21.

Doxa. 1999. Gli stranieri in Italia. Bollettino della Doxa 44(17-18).

Dustmann, Christian and Ian Preston. 2001. Attitudes to ethnic minorities, ethnic context and location decisions. The Economic Journal 111:353-373.

Ervasti, Heikki. 2004. Attitudes towards foreign-born settlers: Finland in a comparative perspective. Yearbook of Population Research in Finland, 40:25-44.

Espenshade, Thomas J. and Katherine Hempstead. 1996. Contemporary American attitudes toward U.S. immigration. International Migration Rewiew 30(2):535-570. 
Gang, Ira N., Francisco L. Rivera-Batiz and Myeong-Su Yun. 2002. Economic strain, ethnic concentration and attitudes towards foreigners in the European Union, Iza, Discussion paper, No. 578.

Maddens, Bart, Jaak Billiet and Roeland Beerten. 2000. National identity and the attitude towards foreigners in multi-national states: the case of Belgium. Journal of Ethnic and Migration Studies 26(1):45-60.

Mayda, Anna Maria. 2004. Who is against immigration? A cross-country investigation of individual attitudes towards immigrants. Iza, Discussion paper, No. 1115.

Moors, Hein, Ingrid Esveldt and Elsbeth van Dam. 2001. Opinions on migrants and migration policy in the Netherlands in a European perspective. Genus 57(3-4):191-213.

Simon, Rita J. and James P. Lynch. 1999. A comparative assessment of public opinion towards immigrants and immigration policies. International migration review 33(2):455-467.

Söderling, Ismo. 1999 The further away you come from, the more unpopular you are as an immigrant to Finland. Paper presented to the Eaps International Conference, The Hague, 30 August-3 September. 
